\title{
DEPLOYMENT STRATEGIES FOR WIRELESS SENSOR NETWORK OVER CLOUD
}

\author{
Engr. Ayaz Ali Gillal \\ BE.Telecom Engineering(MUET Jamshoro), CCNA, CCNP. MCSE \\ M.E (CCN) QUEST Nawabshah \\ IT, Khairpur Medical College, Khairpur Mir's
}

Engr. Muhammad Afzal Junejo

M.E (CCN) QUEST Nawabshah
Engr. Muhammad Iftikhar Umrani

Lecturer SZIBIST Larkana

\begin{abstract}
Wireless Sensor Network and Cloud Computing has become the cutting edge technologies, more attention has been paid to the further development due to ubiquitous sensing and communication devices that would soon be integrated into our daily life, to provide information and convenience wherever and whenever we need. These two paradigms have many challenges like it demands scalable architecture along with energy efficient algorithm to ensure good Quality of service. The data which extracted from Wireless Sensor Network is not utilized adequately due to the lack of expertise, time and money. Prospective can help the data to be explored and stored for better use in future. In my research, I will present a survey that how the valuable data of wireless sensor can be more efficiently and widely used by different applications when it is integrated with cloud computing. I will highlight its key concepts, state-of-the-art implementation, data analysis, security measures, architectural principles as well as research challenges. The aim of my research is to provide a better understanding of the design challenges \& Deploying strategies of wireless sensor network over cloud and identify important research directions and future enhancements.
\end{abstract}

\section{INTRODUCTION}

Wireless Sensor Network is appear to be the most cutting edge and emerging field for low power wireless communication, in which real-time specific sensor data helps different application to avail benefit from it. Wireless Sensor Networks consists of inexpensive, selfpowered devices called nodes responsible for sensing and local preprocessing are interconnected with wireless connections that interact with environment by sensing or controlling environmental parameter like movements, temperature, pressure, humidity and light etc. The single node can't perform alone, these nodes have to collaborate in order to fulfill their tasks by using wireless communication. These nodes don't need manual intervention, new nodes auto adjust with existing network and reconfigure their links and find alternate paths.

\section{COMPONENTS}

Field: Area where Node are places.

Sensor Nodes: There are tiny devices that collect information and route to sink.

Sink: It is data aggregation point that receive, process and store data from other node.

Base Station: It is centralized point which collect information form WSN.

(Ming Liu 2005, Bala 2018, Daniel 2018)

Cloud Computing

Cloud computing has recently emerged as a new paradigm for hosting and delivering services over the Internet. Cloud computing is referred as applications and services rendered to consumers through internet. Those who manage cloud platform lease resources and provide several features according to the usage based and service provider rent resources to serve the end users.(J.SRINIVAS1 2012)

These services put forwarded 3 models: 


\section{International Journal of Engineering Applied Sciences and Technology, 2020 Vol. 4, Issue 10, ISSN No. 2455-2143, Pages 34-36 \\ Published Online February 2020 in IJEAST (http://www.ijeast.com)}

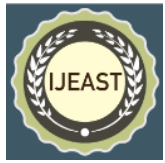

1. Software as a Service (SAAS): It is available to users through internet and run by cloud service provider and mostly used by organizations.

2. Platform as a Service (PAAS): It can be executed without any administrative expertise and used for developing Websites without installing any software on the system by developers.

3. Infrastructure as Service (IAAS): It is operated, maintained and control by cloud service providers that support various operations like storage, hardware, servers and networking.

Types of Cloud:

Public clouds: A cloud in which service offers to the general public.

Private clouds: It offers the highest degree of control over performance, reliability and security.

Hybrid clouds: It combination of public and private cloud in which one part of the service infrastructure runs in private clouds while the remaining part runs in public clouds.

Virtual Private Cloud: It uses the limitations of both public and private clouds and leverages virtual private network (VPN) technology that allows service providers to design their own topology and security settings such as firewall rules. (Zhang, Cheng et al. 2010, Qaisar 2012).

\section{MERGING OF TWO TECHNOLOGIES, ARCHITECTURE AND DESIGN.}

The main objective to merge these two paradigms is to facilitate the shift of data from wireless sensor network to the cloud so that the valuable data may be fully utilized in all aspects. It will be also ease sharing data over internet and will be useful exploited for a large number of different applications. It also make information easily accessible, stored and analyzed not only locally but from everywhere around the world. WSN are limited in their processing power, battery life and communication speed on other side cloud computing usually offers the opposite, which makes it attractive for long term observations, analysis and use in different kinds of environments and projects, since the basic infrastructure remains the same.(Swathi B S1 2014) The combination of WSN with cloud computing will provide benefit to organizations and research community for centuries. WSN has the advantage that different king of devices and programing languages can be used and easily interconnected. Recent advances in the field of artificial intelligence, big data, and cloud computing, as well as concurrent attempts in standardization in low-power wireless networking and security, are paving the way for the commercialization of WSN applications with the commercial ecosystem.(Ahmed and Gregory 2011)
Sensor Cloud Virtualization: It uses the physical sensor that gathers the data and transmit to the cloud infrastructure, It handles data efficiently. It uses internet as source of communication between physical and cyber

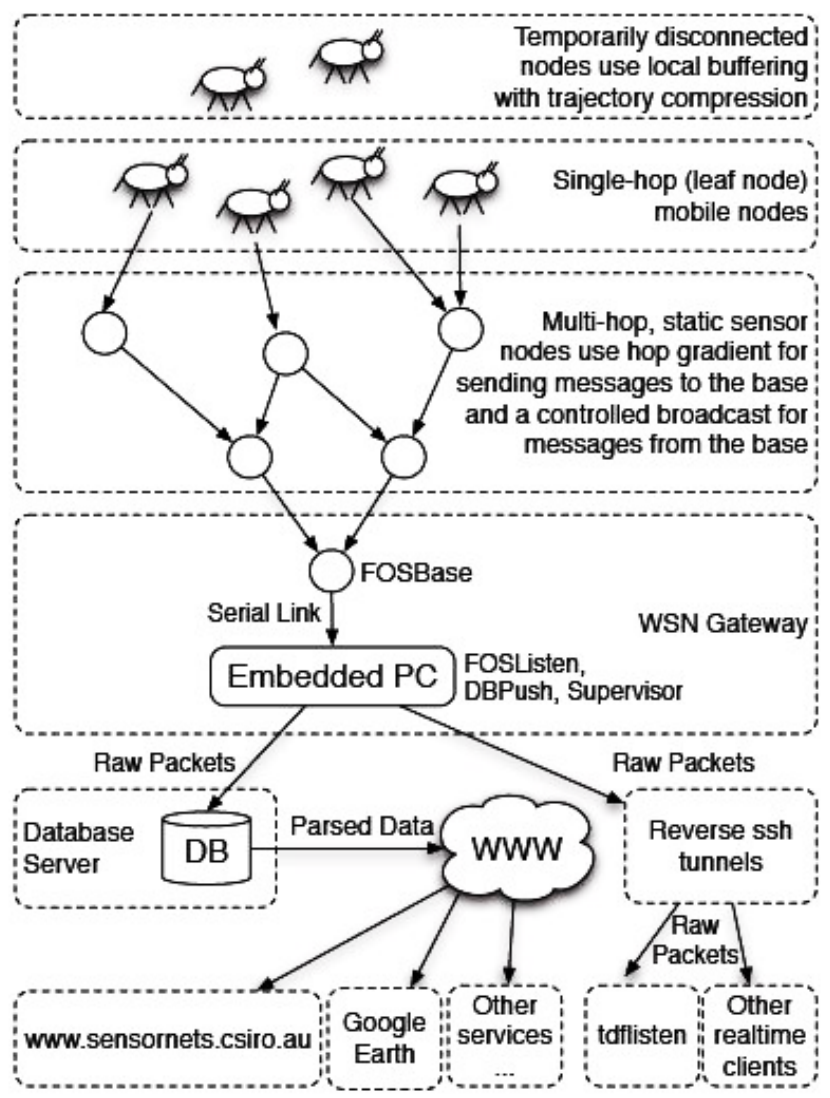

world. The computational devices act like virtual sensor that allow end users to access the sensor's data (K.Lakshmanarao 2013)

\section{APPLICATIONS OF WSN BASED CLOUD COMPUTING}

It can be used in military, environmental activities, battle field surveillance, border security surveillance, motion tracking, health, Transport Monitoring, Structural Health monitoring, Industrial monitoring, Volcano monitoring, Air pollution monitoring, Greenhouse monitoring, Landslide detection, Forest fires detection, Water/wastewater monitoring, Agriculture, and commercial applications.

SCENARIO: Rainforest rehabilitation by CSIRO technology:

The CSIRO ICT Centre has deployed WSN nodes in the rainforest to measure conditions. The sensors monitor rainfall, cloud cover, soil moisture, wind speed \& direction, carbon dioxide concentration, air temperature, sunshine and fog density. The data collected will be 


\section{International Journal of Engineering Applied Sciences and Technology, 2020 Vol. 4, Issue 10, ISSN No. 2455-2143, Pages 34-36 \\ Published Online February 2020 in IJEAST (http://www.ijeast.com)}

available through the Cloud, used at a time of global warming may be considerable.(Peter Corke 2010).

\section{ISSUES AND CHALLENGES}

The WSNs and Cloud Computing continue to grow and become widely used by many applications today. However merging of these two technologies suffers from many constraints like limited energy, processing capability, storage capability, as well as unreliable communications, unattended operations, and security problems etc.(Sen 2009) The main issue in combination of these two is the remote communication between the WSN hubs and the cloud which is much slower. The WSN must to design to emphasize on strategies to improve signals reception, design of low cost, less power sensor and processing units.(Sharma, Bansal et al. 2013)

\section{FUTURE SCOPE}

In next generation

1. WSN will benefit when sensors data is added to blogs, virtual communities and social network applications.

2. Sensing and Communication devices would soon be integrated to daily life.

3. WSN with mobile networks

4. WSN can be more beneficial with the use of Artificial Intelligence.

5. WSN data can be stored via cloud for centuries and can be beneficial for number of generations.

6. The combination of WSN with cloud network will create lot of opportunities for new business models

\section{CONCLUSION}

This paper surveyed the Cloud Computing and wireless sensor network both the technologies in detail and also their impact when integrated with each other for the benefit of organizations. The above framework also clarifies the strategy for integrating the WSN with Cloud. This technology will attract attention of research community of WSN and cloud computing to work together and develop compatible techniques and algorithm for future development.

\section{REFERENCES}

1. Ahmed, K. and M. Gregory (2011). Integrating Wireless Sensor Networks with Cloud Computing. 2011 Seventh International Conference on Mobile Ad-hoc and Sensor Networks: $364-366$.

2. Bala, A. (2018). "Security Attacks and Challenges of Wireless Sensor Network." International Journal of Scientific Research in Computer Science, Engineering and Information Technology Volume 3(Issue 1).

3. Daniel, P. C. a. A. K. (2018). "Wireless Sensor Networks-A Survey." Proc. of Int. Conf. on Recent Trends in Information, Telecommunication and Computing, ITC.

$4 . \quad$ J.SRINIVAS1 (2012). "CLOUD

COMPUTING BASICS." International Journal of Advanced Research in Computer and Communication Engineering 1(5): 5.

5. K.Lakshmanarao, C. R. V., K.Kanakavardhini (2013). "Survey on different issues of Sensor-Cloud." International Journal of Engineering Research \& Technology (IJERT) 2(10): 6 .

6. Ming Liu, W. L. (2005). "Coverage Analysis for Wireless Sensor Networks." https://www.researchgate.net/publication/225801057.

7. Peter Corke, F., IEEE, John Doe, Fellow, OSA, and Jane Doe, Life Fellow, IEEE (2010). "Environmental Wireless Sensor Networks." PROCEEDINGS OF IEEE, SPECIAL ISSUE ON EMERGING SENSOR NETWORK APPLICATIONS. 8. Qaisar, S. (2012). "Cloud computing: Network/security threats and countermeasures." INTERDISCIPLINARY JOURNAL OF CONTEMPORARY RESEARCH IN BUSINESS VOL 3 ,

9. Sen, J. (2009). "A Survey on Wireless Sensor Network Security." International Journal of Communication Networks and Information Security (IJCNIS) 1(2): 24.

10. Sharma, S., R. K. Bansal and S. Bansal (2013). Issues and Challenges in Wireless Sensor Networks. 2013 International Conference on Machine Intelligence and Research Advancement: 58-62.

11. Swathi B S1, D. H. S. G. (2014). "Integration of Wireless Sensor Networks and Cloud Computing." IPASJ International Journal of Computer Science (IIJCS) 2(5): 5.

12. Zhang, Q., L. Cheng and R. Boutaba (2010). "Cloud computing: state-of-the-art and research challenges." Journal of Internet Services and Applications 1(1): 7-18. 